\title{
Percepção de alunos de curso técnico de contabilidade sobre a escolha profissional
}

\author{
The perception of students from the technical course of Accounting on professional choice
}

Luiz Ricardo Vieira Gonzaga ${ }^{[a]}$, Sônia Regina Fiorim Enumo ${ }^{[b]}$

\footnotetext{
${ }^{[a]}$ Doutorando em psicologia pela Pontifícia Universidade Católica de Campinas, Campinas, SP Brasil, e-mail:

luiz.rvg1@puccampinas.edu.br

${ }^{[b]}$ Doutora em psicologia, professora do Programa de Pós-Graduação em Psicologia da Universidade Católica de Campinas, Campinas, SP - Brasil, e-mail:

sonia.enumo@puc-campinas.edu.br
}

Recebido: 24/09/2012

Received: 09/24/2012

Aprovado: 25/03/2013

Approved: 03/25/2013

\section{Resumo}

A escolha profissional é um processo contínuo, composto de decisões complexas tomadas ao longo da vida. Este estudo avaliou a percepção de estudantes sobre escolha profissional. Participaram 17 alunos do curso técnico de Contabilidade, do período noturno, em Campinas, SP, a maioria mulheres $(70,6 \%)$, com idade entre 17 e 35 anos $(M=23,2)$, que responderam um questionário com quatro questões (três abertas). A análise de conteúdo das respostas classificou-as em três categorias e nove subcategorias: I - Motivos da escolha profissional: a) afinidade pela profissão aliada ao surgimento de oportunidades na área; b) influência do grupo social de referência; II - Estabilidade financeira e reconhecimento social: a) estabilidade financeira; b) reconhecimento social; III - Características pessoais desejáveis na profissão: a) competências/atitude/comportamento; b) habilidades sociais e cognitivas; IV - Dificuldades na escolha profissional: a) incerteza na escolha profissional; b) dificuldades acadêmicas do curso/profissão; c) afinidade pela área versus comprometimento profissional. Estavam inseridos no mercado de trabalho, na área escolhida, $41 \%$ da amostra; e 33\% estavam indecisos quanto à escolha profissional. 0 curso foi escolhido pela afinidade com a profissão, aliado às oportunidades nessa área de trabalho (82,35\%). 0 grupo social de referência influenciou a escolha de $17,64 \%$ dos estudantes, que valorizam o reconhecimento social da profissão. Ela exige um perfil caracterizado por habilidades de autorregulação comportamental e emocional, além de habilidades cognitivas. Analisar esses fatores permite ter uma visão mais abrangente sobre a maturidade na escolha profissional, de forma que ela seja bem constituída e congruente.

Palavras-chave: Escolha profissional. Valores sociais. Estudante. 
emergence of opportunities in the area; b) influence of social reference group; II - Financial stability and social recognition: a) financial stability; b) social recognition; III - Personal characteristics desirable in the profession: a) skills/attitude/behavior; b) social and cognitive skills; IVDifficulties in career choice: a) uncertainty in career choice; b) academic difficulties of the course/ profession; c) affinity for area versus professional commitment. Were inserted in the labor market, in the chosen field, $41 \%$ of the sample; and 33\% were undecided as to the professional choice. The course was chosen for its proximity to the profession, coupled with the opportunities on the area (82.35\%). The social reference group influenced the choice of $17.64 \%$ of students who value the social recognition of the profession. It requires a profile characterized by behavioral and emotional skills of self-regulation and cognitive skills. Analyzing these factors provides a more comprehensive view of maturity in their career choice, so that it is well organized and consistent.

Keywords: Professional choice. Social values. Student.

\section{Introdução}

A escolha profissional não é um ato isolado, mas um processo contínuo, composto de decisões tomadas, em certos momentos, ao longo da vida (Filomeno, 2005; Neiva, 2007). Tal processo é visto como característico da adolescência pelo fato do jovem deparar-se com uma série de escolhas que definirão seu futuro, entre elas, a profissão (Almeida \& Pinho, 2008).

Para Mansano (2003), a escolha mais apropriada e definitiva é um fato ilusório, na medida em que é percebida como única. É como se o indivíduo, ao passar da adolescência para a vida adulta, estivesse isento de uma série de outras escolhas na vida, obtendo automaticamente a estabilidade, a harmonia e a maturidade que tanto almeja. A escolha da profissão é apenas a primeira grande escolha, para aquele momento e em determinadas condições, de uma variada sucessão de escolhas que o jovem terá que realizar ao longo de sua carreira profissional (Lemos \& Ferreira, 2004; Soares, 2002). Pinto (2003) reforça que escolhas acompanham o indivíduo em toda a sua vivência emocional, e qualquer escolha implica, consequentemente, na renúncia de outras opções.

Contudo, a primeira escolha profissional passou a ser considerada pela sociedade contemporânea como um problema específico da fase da adolescência, tendo que ser resolvido com urgência (Mansano, 2003). Por outro lado, Moura (2008) acha que a incerteza da escolha profissional não seria apenas um problema específico dessa fase, pois há outros fatores intervenientes que são comuns a outras fases do desenvolvimento, como as decisões em relação às atribuições profissionais e à reorientação de carreira. Essas dificuldades provavelmente seriam mais pontuadas na fase da adolescência porque é nela que o jovem entra em contato, em um primeiro momento de escolha, com um curso de preparação profissional, ou tem a possibilidade de entrar no mercado de trabalho. Essa situação implica em uma responsabilidade que irá marcá-lo no percurso da sua trajetória profissional. 0 processo de escolha irá remeter o jovem à inserção em uma realidade multiprofissional, em um mercado de trabalho em constante transformação. Ocorre também, temporalmente, o processo de construção e desconstrução, não apenas da profissão, mas em nível mais amplo, que seria a própria trajetória de vida (Gabaldi, 2002; Mansano, 2003).

Na tentativa de fazer a escolha correta, facilmente se nega o fato de que, no decorrer da vida profissional, o sujeito irá deparar-se, outras vezes, com novas situações de decisão, as quais poderão levá-lo por novos rumos até então sequer por ele pensados (Mansano, 2003). Nesse sentido, toda decisão envolve dificuldades porque implica em escolhas, sendo que, na área profissional, o grau de dificuldade aumenta pelo fato de existirem inúmeras áreas a escolher dentro da mesma profissão (Lemos \& Ferreira, 2004; Moura, 2008).

A escolha de uma determinada ocupação não envolveria apenas a atividade laboral, mas o local e o clima organizacional, a rotina da atividade, os colegas de profissão no qual esse jovem irá relacionar-se. Há também "os ganhos" que ele poderá obter através do trabalho, como o salário, o 
reconhecimento, o plano de carreira, a promoção, a participação nos lucros ou resultados (PLR), entre outros (Neiva, 2007).

A análise e a relação desses fatores supramencionados são importantes para que haja uma tomada de decisão consciente e ajustada por parte dele. Esse processo de escolha irá, muitas vezes, ser reeditado em outros períodos da vida desse jovem, como na saída da universidade, na escolha do curso de pós-graduação, no campo de trabalho, no primeiro emprego. Estando empregado, o processo se repete em diversos momentos da carreira profissional: mudança de cargo ou emprego, desemprego e, por fim, na aposentadoria, quando o indivíduo restabelece novos projetos para a sua vida pessoal e profissional (Neiva, 2007).

Lucchiari (1993) salienta que, para facilitar a escolha, devem ser analisados os seguintes aspectos quanto ao conhecimento das profissões: a) quem são os profissionais da área escolhida, o que fazem, como e onde; b) o mundo laboral dentro do sistema político-econômico vigente; c) as possibilidades de atuação no mercado de trabalho. Para isso, é importante a realização de visitas aos locais de trabalho, nos cursos e laboratórios de pesquisa nas universidades, obter informações sobre currículos e fazer entrevistas com profissionais da área de interesse.

A dimensão temporal da escolha da profissão também é importante. Essa escolha precisa ser integrada e percebida pelo jovem, pois é o momento presente que definirá o futuro profissional desse adolescente, baseado, concomitantemente, em experiências e conhecimentos passados (Almeida \& Pinho, 2008; Soares, 2002). Por outro lado, relação da escolha profissional com a temporalidade é complexa, sendo importante a compreensão e a integração destes dois fenômenos pelo jovem (Soares, 2002).

Almeida e Pinho (2008) enfatizam que o adolescente que escolhe uma profissão encontra-se numa fase de transição, de mudanças, de adaptação e de ajustamento, quando deixa para trás a fase da infância, adentrando-se, dessa maneira, na vida adulta. Assim Filomeno (2005) resume esse contexto: “[...] são mudanças que ocorrem na passagem da infância à idade adulta para os quais o indivíduo deve encontrar diferentes modos de adaptação." (p. 35).

A escolha profissional, portanto, torna-se um momento difícil para o jovem, pois, além de ter que enfrentar uma série de dificuldades próprias da adolescência, como mudanças físicas, cognitivas, morais e sociais, ele se confronta ainda com mais uma questão, relativa à decisão profissional, o que faz dessa escolha um momento crítico (Filomeno, 2005; Moura 2008). Segundo Dias (1995), “[...] torna-se inegável, portanto, que a decisão profissional entrelaça-se com todas as outras áreas da vida do indivíduo" (p. 73). Dessa forma, a escolha não se remete apenas à decisão do que fazer, mas também ao que o indivíduo quer ser, interferindo nos seus valores, estilo ou modo de vida (Neiva, 2007).

Quando quem decide é o jovem, a escolha é geradora de mais conflitos, em função não apenas das características da própria escolha, mas também das consequências que poderão acarretar no futuro (Moura, 2008). Escolher uma profissão significará a escolha de uma atividade laboral à qual será dedicada boa parte da vida futura (Gabaldi, 2002). É nessa sucessão de resolução de conflitos que o adolescente se depara com a necessidade de implementar uma série de escolhas relativas ao seu futuro escolar e profissional (Almeida \& Pinho, 2008).

Segundo Gabaldi (2002), o comportamento de escolher uma profissão constitui-se como um ato muito importante, pois supera em ordem de importância qualquer outra decisão. Abrange, ao mesmo tempo, outras variáveis, como as circunstâncias materiais, o ambiente de vida, as possibilidades internas e externas de desenvolvimento, as probabilidades de progresso, a duração da saúde, as futuras circunstâncias familiares, o nível cultural, a posição social, a dependência ou independência profissional. A escolha seria um comportamento que faz parte do repertório do indivíduo e que irá depender do tipo de reforço que ele espera com sua escolha (Ivatiuk, 2004).

Essa escolha está permeada também de variáveis multifatoriais, determinadas pela família, professores, colegas, escola, tecnologia e meios de comunicação (rádio, revistas, jornais, programas de televisão e sites), que são vistos como elementos influentes no processo decisional do adolescente (Moura, 2000). Soares (2002) aponta alguns dos processos determinantes na escolha profissional, que envolveriam fatores políticos, econômicos, sociais, educacionais, familiares e psicológicos. São eles: a) fatores políticos: referem-se especialmente à política governamental e seu posicionamento perante a educação; b) fatores econômicos: referem-se ao mercado de trabalho, ao retorno financeiro, ao desemprego, à 
instabilidade financeira, à perda do poder aquisitivo da classe média e a todas as consequências do sistema capitalista no qual vivemos; c) fatores sociais: refere-se à divisão da sociedade em classes sociais, à desigualdade no acesso ao ensino superior, às diferenças de oportunidades e às realidades influenciando na escolha, à busca de ascensão social por meio do Ensino Superior, aos efeitos da sociedade no ambiente familiar, e ao impacto da globalização na cultura e na família; d) fatores educacionais: correspondem ao sistema de ensino brasileiro, à necessidade e ao prejuízo do vestibular, à falta de investimentos financeiros na educação pelo governo, ao sistema de ensino superior público e privado; e) fatores familiares: compreende as expectativas familiares diante da escolha profissional dos filhos; e f) fatores psicológicos: dizem respeito aos interesses, às motivações, às habilidades, às competências pessoais, e à compreensão das informações que o indivíduo possui versus a desinformação na qual ele está submetido. Esses fatores, aliados a outros, irão determinar a escolha dos indivíduos, sendo importante analisá-los, buscando compreendê-los em sua inter-relação.

Assim, objetivou-se, neste estudo, analisar a percepção de estudantes de uma escola técnica estadual do curso técnico em Contabilidade sobre sua escolha profissional.

\section{Método}

\section{Participantes}

A amostra deste trabalho foi constituída por 17 estudantes do curso técnico de Contabilidade, no período noturno de uma escola técnica estadual da cidade de Campinas, no interior do Estado de São Paulo, sendo a maioria mulheres $(n=12 ; 70,6 \%)$.

Os participantes tinham entre 17 e 35 anos $(M=$ $23,2$ anos; $\pm 6,10)$. A maioria era solteira $(n=11)$; $13(76,5 \%)$ trabalhavam; e a maioria tinha Ensino Médio ou Técnico (88,2\%) e 11,7\% do Ensino Superior.

\section{Instrumentos}

Foi elaborado um questionário com quatro questões (três abertas e uma fechada), com o objetivo de avaliar a percepção dos alunos sobre a escolha profissional. A primeira questão foi direcionada às dificuldades presentes em relação à profissão; na segunda questão, perguntou-se o que havia levado o respondente a escolher a profissão pretendida; na terceira questão, solicitou-se que descrevessem as qualidades, habilidades e comportamentos importantes para o perfil profissional; e, na última questão, pediu-se que fosse comentada a afirmação sobre a relação entre escolha profissional, estabilidade financeira e reconhecimento social.

\section{Procedimento}

Em um primeiro momento, foi enviada uma carta de anuência à Coordenação Escolar da Escola Técnica explicando os objetivos do estudo. Após a permissão, foi feito o convite aos estudantes matriculados no curso técnico de Ciências Contábeis para participarem de forma voluntária. Os 17 participantes interessados em participar do estudo assinaram o Termo de Consentimento Livre e Esclarecido (TCLE) e foi aplicado o questionário. A coleta de dados foi realizada em uma sessão, com a duração aproximada de 60 a 120 min, dependendo da dificuldade apresentada pelo participante. A devolução dos dados aos estudantes foi feita em grupo.

\section{Resultados e discussão}

Procedeu-se à leitura e transcrição das respostas dos estudantes ao questionário, classificando o conteúdo de cada questão por grau de proximidade das respostas e de acordo com a compreensão obtida. Foi possível, assim, elaborar quatro categorias amplas: I- Motivos da escolha profissional; II- Estabilidade financeira e reconhecimento social; III- Características pessoais desejáveis na profissão; e IV- Dificuldades na escolha profissional; que foram subdivididas em nove subcategorias para a classificação dos conteúdos analisados. As respostas foram analisadas de acordo com os objetivos da pesquisa, a partir das categorias estabelecidas na análise de conteúdo, com base em Bardin (2004) (Tabela 1). 
Tabela 1 - Variáveis da escolha profissional por estudantes do Curso Téenico de Contabilidade $(\mathrm{N}=17)$

\begin{tabular}{llc}
\hline Categoria & Subcategorias & fa (\%) \\
Motivos da escolha profissional (N = 39) & $\begin{array}{l}\text { Afinidade pela profissão aliada ao surgimento } \\
\text { de oportunidades na área }\end{array}$ & $14(82,4)$ \\
& Influência do grupo social de referência & $3(17,6)$ \\
Subtotal de respostas & & $17(100,00)$ \\
Estabilidade financeira e reconhecimento & *Estabilidade financeira & $13(44,8)$ \\
social (N = 29) & *Satisfação pessoal e social & $16(55,2)$ \\
& & $29(100,00)$ \\
Subtotal de respostas & Competências, Atitudes e Comportamentos & $42(73,7)$ \\
Características pessoais desejáveis na & Habilidades sociais e cognitivas & $15(26,3)$ \\
profissão & & \\
(N = 57) & & $57(100,00)$ \\
Subtotal de respostas & Dificuldades acadêmicas do curso/profissão & $16(41,00)$ \\
Dificuldades na escolha profissional $(\mathrm{N}=39)$ & Incerteza na escolha profissional & $13(33,3)$ \\
& Afinidade pela área versus comprometimento profissional & $10(25,6)$ \\
Subtotal de respostas & & $39(100,00)$ \\
\hline
\end{tabular}

Nota. *respostas induzidas.

\section{Categoria I - Motivos para a escolha da profissão}

Dois motivos básicos justificaram a escolha do curso: a) a afinidade pela profissão aliada ao surgimento de oportunidades na área e b) a influência do grupo social de referência (Tabela 1).

A afinidade pela profissão aliada ao surgimento de oportunidades na área foram os motivos mais citados (82,3\% dos 17 participantes), referindo-se à escolha profissional como congruente com a afinidade pela profissão, de modo que o surgimento de oportunidades de trabalho implicará em mais autoconfiança e na necessidade de autodesenvolvimento profissional. Os comentários apresentados a seguir ilustram essa situação:

"Estou fazendo Técnico Contábil, pois trabalho em um escritório de Contabilidade." ( $\mathrm{E}_{4}$, sexo feminino, 18 anos, trabalha na área);

"Hoje escolhi contabilidade para me auxiliar na nova vaga que assumi, que vem me ajudando muito" ( $\mathrm{E}_{6}$, sexo feminino, idade não informada, trabalha na área);

"Minha facilidade de compreensão com a área e por gostar da matéria" ( $\mathrm{E}_{9}$, sexo feminino, 19 anos, trabalha em outra área);

"O que me levou a escolher a profissão foi ter tra- balhado na área como auxiliar contábil. Foi uma experiência boa e me identifiquei com a área" $\left(\mathrm{E}_{11}\right.$, sexo feminino, 21 anos, desempregada).

Com menor frequência, foi citada a influência do grupo social de referência $(17,6 \%)$ como decisiva para a escolha do curso (Tabela 1). Foi possível identificar que a tomada de decisão frente à profissão escolhida corresponde a um processo multifatorial. Nele há influências determinadas tanto pelos processos psicológicos (aspectos motivacionais, perfil de interesse, habilidades, por exemplo), quanto pelos sociais, como as variáveis externas relacionadas à família, à escola, aos amigos, entre outros. É possível ver esses aspectos nos relatos a seguir:

"Influência familiar e curiosidade, pois foi uma área que me mostrou bastante reconhecimento" ( $\mathrm{E}_{8^{\prime}}$ sexo feminino, 18 anos, trabalha em outra área);

"Familiares atuarem na área" ( $\mathrm{E}_{7}$, sexo masculino, 18 anos, trabalha em outra área);

"Exemplo de pessoas que conheço, que me fizeram despertar um interesse pela área" $\left(\mathrm{E}_{10}\right.$, sexo feminino, 18 anos, trabalha em outra área).

Convém ressaltar que não se pode subestimar o papel dos aspectos psicossociais mencionados, pois 
eles podem ampliar ou limitar as possibilidades de escolha, restringir ou alargar as oportunidades de formação ou de preparo do elemento humano, nos diferentes níveis reclamados pelo mercado de trabalho que o espera (Freitas, 1969).

\section{Categoria II - Estabilidade financeira e reconhecimento social}

Frente à pergunta direta sobre a profissão permitir uma estabilidade financeira e reconhecimento social, a maioria dos estudantes considerou que o reconhecimento social é mais importante $(55,2 \%$ de 29 respostas) (Tabela 1 ).

A escolha profissional baseada na busca pela satisfação pessoal e social estava atrelada à satisfação pessoal, ao gosto do indivíduo e ao reconhecimento social que essa profissão iria proporcionar. Dessa maneira, há a necessidade, por ordem de importância, na busca por uma profissão que una afinidade, interesse, reconhecimento profissional, social e satisfação financeira. Pode-se observar essa evidência em algumas dos relatos a seguir:

"Fazer o que gosta é importante" ( $\mathrm{E}_{10}$, sexo feminino, 18 anos, trabalha em outra área);

"Prefiro essa: Gosto do que faço e ainda sou pago por isso" $\left(\mathrm{E}_{3}\right.$, sexo feminino , 22 anos, trabalha na área).

Bardagi, Lassance, Paradiso e Menezes (2006) afirmam que, em um contexto de formação profissional, como ocorre no período de formação universitária, a satisfação é compreendida como um sentimento de identificação, ajustamento à área de formação e comprometimento. Perspectivas quanto ao mercado de trabalho e às possibilidades de inserção nele também parecem ser importantes para a satisfação.

Por outro lado, a segurança financeira correspondeu a $44,8 \%$ das 29 respostas dadas. Percebe-se aqui o impacto de um futuro promissor relacionado a uma profissão que gere estabilidade financeira ao indivíduo. Pode-se observar essa evidência nas frases:

"Quem não gostaria de ter estabilidade financeira.... ( $\mathrm{E}_{1}$, sexo feminino, 33 anos, trabalha em outra área);

“Com certeza, todos nós buscamos uma profissão que nos traga estabilidade financeira" $\left(\mathrm{E}_{5}\right.$, sexo masculino, 35 anos, trabalha em outra área).

\section{Categoria III - Características desejáveis na profissão}

As qualidades, habilidades ou comportamentos importantes para a profissão citados pelos estudantes incluíram descrições de competências, atitudes e comportamentos, e habilidades sociais e cognitivas. Apenas um estudante teve dificuldades em identificar as suas qualidades, não respondendo a questão (Tabela 1).

As competências, atitudes e comportamentos elencados $(73,7 \%$ das respostas) referem-se ao contexto de interação do sujeito com o ambiente ou meio social em que ele está inserido. As respostas relacionaram-se a habilidades de autorregulação comportamental e emocional, que favorecem o engajamento profissional, como a organização, dedicação, tranquilidade, comprometimento, paciência, gentileza, honestidade, entre outras características pessoais. Os relatos a seguir ilustram essas habilidades:

\begin{abstract}
"Responsabilidade, organização, retidão, honestidade. $O$ bom profissional é atencioso e gentil" ( $\mathrm{E}_{10}$ sexo feminino, 18 anos, trabalha em outra área);

"Esforçada, comunicativa, atenciosa, paciente. Essas qualidades aprendi com o tempo" $\left(\mathrm{E}_{3}\right.$, sexo feminino, 22 anos, trabalha na área).
\end{abstract}

Foram citadas também algumas habilidades sociais e cognitivas consideradas relevantes para a profissão (26,3\% de 57 respostas) (Tabela 1). Os aspectos sociocognitivos referem-se às fontes internas do sujeito, que seriam as habilidades cognitivas ou mentais, que favorecem a competência e a segurança, e aspectos neurobiológicos, como raciocínio, lógica, aprendizagem e a mediação do sujeito com os reforçadores do ambiente social para o desenvolvimento dessas habilidades. Nos relatos seguintes, podem-se compreender alguns desses aspectos:

"Atenção total é o principal, concentração, pensamento lógico e rápido, entre outras coisas" ( $\mathrm{E}_{10}$ sexo feminino, 18 anos, trabalha em outra área);

"Concentração, facilidade em trabalhar com números" ( $\mathrm{E}_{7}$, sexo masculino, 18 anos, trabalha em outra área). 
Categoria IV - Dificuldades na escolha profissional

As respostas relacionadas às dificuldades na escolha profissional dadas pelos estudantes de nível técnico se relacionam a três temas: a) as dificuldades acadêmicas do curso/profissão (41\% das 39 respostas nesta categoria); b) as incertezas na escolha profissional (33,3\%); e c) a afinidade pela área versus o vínculo profissional $(25,6 \%)$. (Tabela 1). Somente um estudante afirmou não ter qualquer dificuldade.

As dificuldades relatadas referem-se ao próprio curso e/ou à profissão, com preocupações com as perspectivas do mercado de trabalho e as dificuldades enfrentadas por aqueles que já trabalham na área, correspondendo a $41 \%$ das 39 respostas (Tabela 1). Podem-se observar essas dificuldades nos relatos a seguir:

"A principal dificuldade é entender completamente sobre tudo nessa área" ( $\mathrm{E}_{10}$, sexo feminino, 18 anos, trabalha em outra área);

"Atualmente, a maior dificuldade é lidar com a cobrança excessiva de metas... Pretendo seguir no ramo, porém em área Administrativa Contábil" $\left(\mathrm{E}_{5}\right.$, sexo masculino, 35 anos, trabalha em outra área); "Tenho dificuldades com a parte fiscal. Pretendo seguir na área de contabilidade" $\left(\mathrm{E}_{13}\right.$, sexo feminino, 26 anos, trabalha em outra área).

A segunda dificuldade mais citada refere-se às incertezas na escolha profissional $333,3 \%$ das 39 respostas) e aborda uma questão peculiar frente aos processos decisórios do estudante, à profissão escolhida e ao futuro profissional almejado por ele (Tabela 1). Tais aspectos puderam ser observados nos seguintes relatos dos estudantes:

"A principal dificuldade na escolha da profissão está em descobrir o que realmente você gosta de fazer e ser bom nisso" ( $\mathrm{E}_{3}$, sexo feminino, 22 anos, trabalha na área);

"Escolher uma profissão é um momento muito difícil da vida... Não sei o que quero para o meu futuro" $\left(\mathrm{E}_{4}\right.$, sexo feminino, 18 anos, trabalha na área).

Essa dimensão temporal da escolha da profissão é extremamente importante, pois a escolha precisa ser integrada e percebida pelo jovem, já que é o momento presente que definirá o futuro profissional desse adolescente (Almeida \& Pinho, 2008; Soares, 2002).

$O$ conflito entre não sentir afinidade pela área ou pelo cargo e ter um comprometimento profissional foi outra dificuldade relatada pelos estudantes $(25,6 \%)$, podendo gerar consequências negativas ao seu futuro profissional, como se vê nos relatos:

"A maior dificuldade é que eu não conhecia a área financeira e estou aprendendo a cada dia. A área qual tenho interesse e gosto é Direito." ( $\mathrm{E}_{6}$, sexo feminino, idade não informada, trabalha na área); "Sinceramente, não pretendo seguir pelo resto da vida a função de assistente contábil, mesmo porque, é muito cansativa e desgasta a pessoa" $\left(\mathrm{E}_{11}\right.$, sexo feminino, 21 anos, desempregada).

\section{Considerações finais}

Ao investigar os motivos e condições para a escolha profissional voltada ao bom desenvolvimento pessoal e profissional de estudantes do ensino técnico de Contabilidade, pôde-se identificar que grande parte não tinha certeza quanto à escolha da profissão, mesmo estando em um curso técnico, na área escolhida por eles no momento. Observou-se também que uma parcela significativa de estudantes já inseridos no mercado de trabalho, na área escolhida, também apresentavam dificuldades, na prática profissional, relativas ao reconhecimento social, à rentabilidade financeira, à afinidade pela área e à falta de comprometimento.

A perspectiva do mercado de trabalho foi outro tema abordado pelos estudantes, que destacaram a exigência de indivíduos competitivos, habilidosos e competentes. Essas condições incentivam o jovem a desenvolver sua escolha profissional de acordo com seu nível de conhecimento acerca da profissão e a analisar sua adaptabilidade para a escolha, além da possibilidade de realização pessoal e financeira que poderá ter futuramente. Nesse contexto, a escolha torna-se um momento difícil para o estudante, pois a tomada de decisão virá acompanhada da consciência do papel que ele irá desempenhar como profissional na sociedade.

Outro aspecto relevante considerado neste estudo foi destacar a realização profissional mediada pelo surgimento de oportunidades na área. A influência de variáveis externas, como a família, o 
grupo de pares foram mencionadas também como um dos aspectos decisivos à escolha profissional e seguimento da carreira.

Os aspectos comportamentais e cognitivos exigidos pela profissão, destacados pelos participantes deste estudo, indicam a necessidade de se averiguar as qualidades, competências e fatores motivacionais em estudos futuros, que elucidem a relação e influência entre essas variáveis e a escolha profissional e a estabilidade no cargo ocupado.

Por fim, espera-se que este estudo possa contribuir aos que se interessam em compreender as questões que afetam o indivíduo e sua escolha profissional mediada pela influência dos aspectos intrínsecos, como os valores sociais. A necessidade de estudar esses fatores supramencionados torna-se necessária para se ter uma visão mais abrangente do processo de escolha profissional, de forma que ela seja bem constituída e congruente.

\section{Referências}

Almeida, M. E. G. G., \& Pinho, L. V. (2008). Adolescência, família e escolhas: implicações na orientação profissional. Psicologia Clínica, 20(2), 173-184.

Bardin, L. (1977). Análise de Conteúdo (L. Reto e A. Pinheiro, trad.). Lisboa: Edições 70.

Bardagi, M., Lassance, M. C. P., Paradiso, A. C., \& Menezes, I. A. (2006) Escolha profissional e inserção no mercado de trabalho: percepções de estudantes formandos. Psicologia Escolar e Educacional, 10(1), 69-82.

Dias, M. L. (1995). Família e escolha profissional. In A. M. Bock (Orgs.), A escolha profissional em questão (pp.71-77). São Paulo: Casa do Psicólogo.

Filomeno, K. (2005). Mitos familiares e escolha profissional: uma visão sistêmica. São Paulo: Vetor.

Freitas, E. (1969). O nível de aspiração no ajustamento profissional. Arquivos Brasileiros de Psicologia Aplicada, 21 (3), 99-105.
Gabaldi, V. M. (2002). Formação de identidade: implicações na escolha profissional. Dissertação de Mestrado não publicada, Programa de Pós-Graduação em Psicologia, Pontifícia Universidade Católica de Campinas, Campinas, SP.

Ivatiuk, A. L. (2004). Orientação profissional para profissões não universitárias: Perspectiva da análise do comportamento. Dissertação de Mestrado não publicada, Programa de Pós-Graduação em Psicologia, Pontifícia Universidade Católica de Campinas, Campinas, SP.

Lemos, C. G., \& Ferreira, M. F. (2004). Geração Zapping e escolha profissional. In Z. B. Vasconcelos, \& I. D. Oliveira (Orgs.), Orientação vocacional: alguns aspectos teóricos, técnicos e práticos (pp.51-60). São Paulo: Vetor.

Lucchiari, D. H. P. S. (1993). O que é orientação profissional? Uma nova proposta de atuação. In D. H. P. S. Lucchiari, M. D. Lisboa, \& K. P. Filho (Orgs.), Pensando e vivendo a orientação profissional (pp.11-16). São Paulo: Summus.

Mansano, S. R. V. (2003). Vida e profissão: Cartografando histórias. São Paulo: Summus.

Moura, C. B. M (2000). Orientação Profissional: Avaliação de um programa sob o enfoque da análise do comportamento. Dissertação de Mestrado não publicada, Programa de Pós-Graduação em Psicologia, Pontifícia Universidade Católica de Campinas, Campinas, SP.

Moura, C. B. (2008). Orientação Profissional sob o enfoque da análise do comportamento (5⿳亠丷⿵冂丶 ed.). Campinas: Alínea.

Neiva, K. M. C. (2007). Processos de escolha e orientação profissional. São Paulo: Vetor.

Pinto, J. M. (2003). Adolescência e escolhas. Coimbra: Quarteto.

Soares, D. H. P. (2002). A escolha profissional: Do jovem ao adulto (2 ${ }^{\mathrm{a}}$ ed.). São Paulo: Summus. 